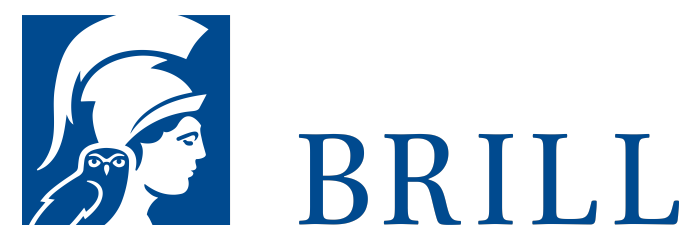

\title{
Werk und Autorschaft
}

\section{Eine Ontologie der Kunst}

Author: Elisabeth Reicher-Marek

Was ist ein Werk? So verschieden die Gegenstände auch sind, die wir als Werke zu bezeichnen pflegen - literarische und musikalische Werke zum Beispiel, aber auch Erfindungen oder Gegenstände der Alltagskultur -, in ontologischer Hinsicht weisen sie wesentliche Gemeinsamkeiten auf. Worin diese Gemeinsamkeiten bestehen, welche Arten von Werken es gibt und worin deren jeweilige Eigenheit besteht, klärt dieses Buch. Ohne die Kategorie der Autorschaft, so zeigt sich dabei, lässt sich gar nicht verstehen, was ein Werk gegenüber anderen Entitäten auszeichnet.

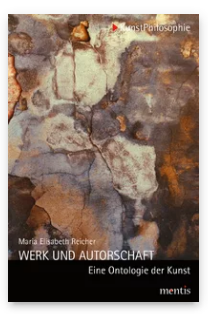

Pages: 208

Seiten

Language:

German

Subjects:

General,

Philosophy

Publisher: Brill | mentis

Series:

KunstPhilosophie, Volume: 11

E-Book (PDF)

Released online:

24 Sep 2019

ISBN: 978-3-

95743-758-7

List price

Paperback

Publication date:

15 Feb 2019

ISBN: 978-3-

95743-102-8

List price 
Maria Elisabeth Reicher, Jahrgang 1966, ist Inhaberin des Lehrstuhls für Philosophie der kulturellen Welt an der RWTH Aachen und Mitherausgeberin der Grazer Philosophischen Studien.

For more information see brill.com

Order information: Order online at brill.com +44330 3330049 | customerservices@brill.com Submission information: brill.com/authors

Titles published by Brill | Fink, Brill | mentis or Brill | Schöningh: +49(o)71 5413279216 | brill@brocom.de 